\title{
AMERICAN PIKAS INHABIT LOW-ELEVATION SITES OUTSIDE THE SPECIES' PREVIOUSLY DESCRIBED BIOCLIMATIC ENVELOPE
}

\begin{abstract}
William G. Simpson ${ }^{1,2}$
ABSTRACT.-It has been suggested that Nearctic pikas (Ochotona spp.) are good biogeographic indicators of regions containing rocky, mesic, and cool habitat characterized by long winters and short summers. I examined whether populations of pikas inhabiting distinct low-elevation locales $(121-255 \mathrm{~m})$ are faithfully restricted to long-winter and shortsummer conditions by monitoring the climate associated with American pikas (Ochotona princeps) in the southern part of the Columbia River Gorge, Oregon. Ambient air temperatures and weather conditions in the vicinity of 4 pika-occupied rockslides were monitored with remote temperature loggers and weather stations from June 2000 to June 2001. Temperatures were compared to long-term averages recorded within the area. I detected pikas inhabiting locales where some temperatures lie outside of the limiting climatic values previously calculated for regions containing pikas. Mild winter temperatures at these pika locations show that long-winter temperatures and snow accumulation associated with typical habitat may not be requirements for pikas in some low-elevation habitat. When using climatic conditions experienced by extant pikas to estimate local paleoenvironments surrounding fossil sites and to anticipate effects of climate change on future pika distributions, I determined that pika sites in the Columbia River Gorge indicate that the association of pikas with long-winter habitat should be considered uncertain. These results highlight the need for further investigation into how local temperatures affect the distribution, behavior, and persistence of low-elevation pikas.
\end{abstract}

Key words: climate change, Columbia River Gorge, low-elevation distribution, Ochotona princeps, paleoecological reconstruction, thermal limits.

American pikas (Ochotona princeps) are small lagomorphs that typically inhabit rocky slopes of montane areas. Rockslides provide pikas places to store vegetation for winter consumption, places to hide from predators, and shelter from extreme temperatures (Smith 1974, MacArthur and Wang 1974, Smith et al. 2004).

American pikas can be at high risk of hyperthermia at ambient temperatures because of their high resting body temperature (mean $40.1{ }^{\circ} \mathrm{C}$ ), low upper lethal body temperature $\left(43.1^{\circ} \mathrm{C}\right)$, and depressed thermal conductance (MacArthur and Wang 1973, Smith 1974). Smith (1974) found notable differences in surface activity and behavioral thermoregulation between pikas at low-elevation (warm) and highelevation (cool) sites. At low elevations, exposure of a pika to ambient air temperatures for only 6 hours (maximum $25.5^{\circ} \mathrm{C}$ ) was lethal when the animal was caged and thus not able to behaviorally thermoregulate. In contrast, 2 similarly caged animals at high elevations each survived a full day without showing any detectable thermal stress. Because of this thermal sensitivity, researchers have suggested that the geographic range of $O$. princeps may be constrained by high temperatures (Grinnell 1917, Smith 1974, Hafner 1993, Beever et al. 2003, Grayson 2005).

The survival of North American pikas may also be correlated to consistently cold winter temperatures. Pikas do not hibernate, and snowpack that accumulates over rockslides acts as a thermal insulator for active pikas. In years when temperatures or precipitation are variable, pika habitat can experience late snow accumulation, early snowmelts, and freezing rain. Without snow insulation, the exposure of pikas to cold temperatures or freezing rain may negatively affect survival by increasing the energy used for thermoregulation (Smith 1978, Smith et al. 2004, Morrison and Hik 2007). On average, low-elevation habitats experience less snow accumulation, thereby increasing the chance that these potentially stressful conditions will not be mitigated by snowpack.

Because of these hypothesized constraints, researchers have attempted to quantify habitat

\footnotetext{
${ }^{1}$ Department of Biology, Portland State University, Portland, OR 97207.

2Present address: Abernathy Fish Technology Center, U.S. Fish and Wildlife Service, 1440 Abernathy Creek Road, Longview, WA 98632. E-mail: william_simpson@fws.gov
} 
restrictions on a regional scale in terms of habitat structure, climate, and elevational displacement (Hafner 1993, Beever et al. 2003, Grayson 2005). Hafner (1993) approximated the bioclimatic envelope of American pikas by compiling NOAA (National Oceanic and Atmospheric Administration) temperature and precipitation data from local and regional patches of their geographic range. Cool habitats were described as areas with short summers and long winters. He found that rangewide, all geographic patches that recently contained pikas experienced an average of $<30$ days per year when air temperatures exceeded $35{ }^{\circ} \mathrm{C}$ (short summers), $>150$ days per year when temperatures fell below $0{ }^{\circ} \mathrm{C}$, and a continuous freeze-free period of $<120$ days (long winters).

By directly examining current ambient temperatures at low-elevation pika habitat, the thermal range and climatic conditions tolerated by pikas both historically and as climate changes can presumably be refined. Investigating atypical pika habitats is important because climatic regimes that are now rare within the geographic range of pikas may have been more widespread historically or might become more widespread in the future. I therefore monitored the local climate at lowelevation sites (121-255 m) inhabited by pikas in the Columbia River Gorge (CRG), Oregon, and compared the results with the approximate thermal limits (ATL) for regions inhabited by pikas as calculated by Hafner (1993). From these data I assessed whether short summers and long winters typically indicative of pikas on a regional scale are good indicators of pika distributions at low-elevation locales in the CRG, and I characterized snowcover and freezing-rain events near CRG sites. Finally, I discuss how these findings relate to the potential use of pikas for thermal reconstruction of paleoenvironments and how these findings may help in anticipating some effects of climate change on future pika distributions.

\section{METHODS}

Temperature and precipitation of the CRG can vary across short geographic distances due to its distinct elevational changes and unique topography (Lynott 1966), particularly in the reach that cuts through the Cascade Mountain Range. The American pika's distribution within the Oregon CRG encompasses much of this intrarange reach (about $44 \mathrm{~km}$ ), where its distribution extends down to $22 \mathrm{~m}$ in elevation. On the Oregon side of the CRG, I searched a total of 37 hours in June and July 2000 for signs of rockslide occupancy by pikas (active and inactive haypiles, feces, sightings, and vocalizations). Searches were conducted between Multnomah Falls and Hood River, Oregon, below $400 \mathrm{~m}$ elevation. To determine the full longitudinal extent of low-elevation pikas in the CRG, I searched most available low-elevation habitat (i.e., rockslides that had historical records of pika presence and rockslides that had no such records). Single transects were walked across each rockslide, and areas with $<2$ individuals vocalizing were searched more thoroughly for pikas or physical evidence of their presence. As a result of this survey, 4 temperature-monitoring sites were chosen to reflect the longitudinal extent of pika distribution in the CRG.

Hobo temperature loggers (Onset Computer Corp., Bourne, MA) recorded the ambient air temperature at 3 of these occupied sites (Multnomah Falls, Tanner, and Wyeth) every 15 minutes between 13 June 2000 and 22 June 2001. As a conservative estimate of temperature at the fourth rockslide, Wygant (elevation $108 \mathrm{~m}$ ), maximum and minimum temperature readings were acquired from a continuously recording National Weather Service station at Hood River, Oregon (elevation $155 \mathrm{~m}$ ). Hood River is about $10 \mathrm{~km}$ east of the Wygant site, making the climate there presumably more continental (i.e., experiences more seasonally extreme temperatures) than at Wygant. I spent 20 minutes monthly searching each site to confirm continued rockslide habitation by pikas throughout the period of monitoring. Since pika vocalizations and surface activity were minimal between November 2000 and February 2001, additional 2-hour winter surveys were conducted at the Multnomah Falls $(n=1)$ and Wygant $(n=2)$ sites during this time. Pika occupation was confirmed by walking transects along rockslide contours at $10 \mathrm{~m}$ apart until pikas called from under the rockslide due to overhead disturbance by the surveyor. Where pikas vocalized, I searched with greater intensity for evidence of long-term habitation (feces, haypiles).

The daily minimum and maximum temperature readings from the 4 sites were compared 
TABLE 1. Thermal characteristics and elevation of pika-occupied sites and a weather station in the Columbia River Gorge, Oregon, between June 2000 and June 2001, as compared with the regional approximate thermal limits and predictors of lower elevational limits generated by Hafner (1993). The number of consecutive freeze-free days recorded by on-site temperature loggers is listed in parentheses after the number calculated using the last spring-freeze day recorded at nearby weather stations.

\begin{tabular}{|c|c|c|c|c|c|}
\hline \multirow[b]{2}{*}{ Localities } & \multicolumn{2}{|c|}{ Temperature $\left({ }^{\circ} \mathrm{C}\right)$} & \multirow[b]{2}{*}{$\begin{array}{l}\text { Consecutive } \\
\text { freeze-free days }\end{array}$} & \multicolumn{2}{|c|}{ Elevation (m) } \\
\hline & $\begin{array}{c}\text { Days } \\
>35^{\circ} \mathrm{C}\end{array}$ & $\begin{array}{l}\text { Days } \\
<00^{\circ} \mathrm{C}\end{array}$ & & $\begin{array}{l}\text { Predicted } \\
\text { lower limit }\end{array}$ & $\begin{array}{c}\text { Actual } \\
\text { site elevation }\end{array}$ \\
\hline All extant habitat & $<30$ & $>150$ & $<120$ & - & - \\
\hline Multnomah Falls & 1 & 48 & $239(140)$ & 1384.2 & 125.7 \\
\hline Tanner & 0 & 62 & $199(155)$ & 1395.3 & 255.0 \\
\hline Wyeth & 0 & 37 & $199(155)$ & 1405.7 & 121.0 \\
\hline Wygant & - & - & - & 1415.7 & 108.3 \\
\hline Hood River, 2000-2001 & 1 & 85 & 151 & $\mathrm{~N} / \mathrm{A}^{\mathrm{a}}$ & 155.4 \\
\hline Hood River, 30-year average & 0 & 83 & 282 & $\mathrm{~N} / \mathrm{A}^{\mathrm{a}}$ & 155.4 \\
\hline
\end{tabular}

aWeather-monitoring station only

with Hafner's (1993) ATL for regions containing pika habitat-sites characterized by short summers, short freeze-free periods, and long winters (Table 1). Temperature loggers were suspended $1.5 \mathrm{~m}$ above ground in shaded areas of each rockslide perimeter. Because weather station temperature loggers are shaded and elevated, the placement of our temperature loggers allowed for thermal comparisons with both the Hood River weather station and the data Hafner (1993) obtained from NOAA. The Hood River weather station and the temperature loggers both calculated daily temperature maxima and minima over a 24 -hour period starting at 08:00. The average daily maximum and minimum temperatures at the Hood River weather station over the previous 30 years (1971-2000) were obtained for comparisons to temperatures recorded there in the summer of 2000 and the winter of 2000-2001. I used Wilcoxon's signedrank tests to determine whether recent CRG temperatures were significantly different from the 30-year average.

A complete year of consecutive freeze-free days was not available because temperature monitoring began in June 2000 and ended in June 2001, and freeze-free periods often encompassed both spring and autumn. Therefore, in 2000 I estimated the last spring freeze day at the pika sites from minimum daily temperature readings at the Bonneville Dam (for the Multnomah Falls site) and Hood River (for the Tanner and Wygant sites) weather stations. Snow accumulation data were also gathered from these weather stations.

I recorded latitude, longitude, and elevation at each rockslide using a Trimble global positioning system unit (vertical accuracy \pm 20 $\mathrm{m})$. To demonstrate how distinctly low in elevation these sites are relative to their latitude and longitude, Hafner's (1993) predictor of the lower-elevational limit of extant pikas (i.e., "pika-equivalent elevation": elevational limit $\left.[\mathrm{m}]=14087-[56.6]\left[{ }^{\circ} \mathrm{N}\right]-[82.9]\left[{ }^{\circ} \mathrm{W}\right]\right)$ was calculated for the location of each rockslide studied and compared to the rockslide's actual elevation.

\section{Results}

The predicted lower-elevational limits for CRG pikas differed strongly from the actual elevations of the 4 pika-inhabited sites I monitored (Table 1). All 4 sites are $>1100 \mathrm{~m}$ below the low-elevational predictors, given each site's latitude and longitude.

Pikas inhabited the CRG sites year-round. These pikas experienced relatively short summers and winters by Hafner's (1993) definitions of these seasons (Figs. 1, 2). Daily temperature maxima exceeded $35{ }^{\circ} \mathrm{C}$ on only 1 day at 2 of the 4 sites (Table 1). These daily temperatures were below the short-summer ATL that all pikas experience on a regional scale. Although regional temperatures associated with all pikas have also been described as "long winter," the number of days that the temperature dropped below $0{ }^{\circ} \mathrm{C}$ among the 4 sites ranged from 37 to 85 days (Table 1 ). This is 1.8 to 4.1 times shorter than the number of days used as a regional ATL for all pika habitat. Pikas also experienced between 151 and 239 consecutive freeze-free days per year, which was between 1.3 and 2.0 times more 


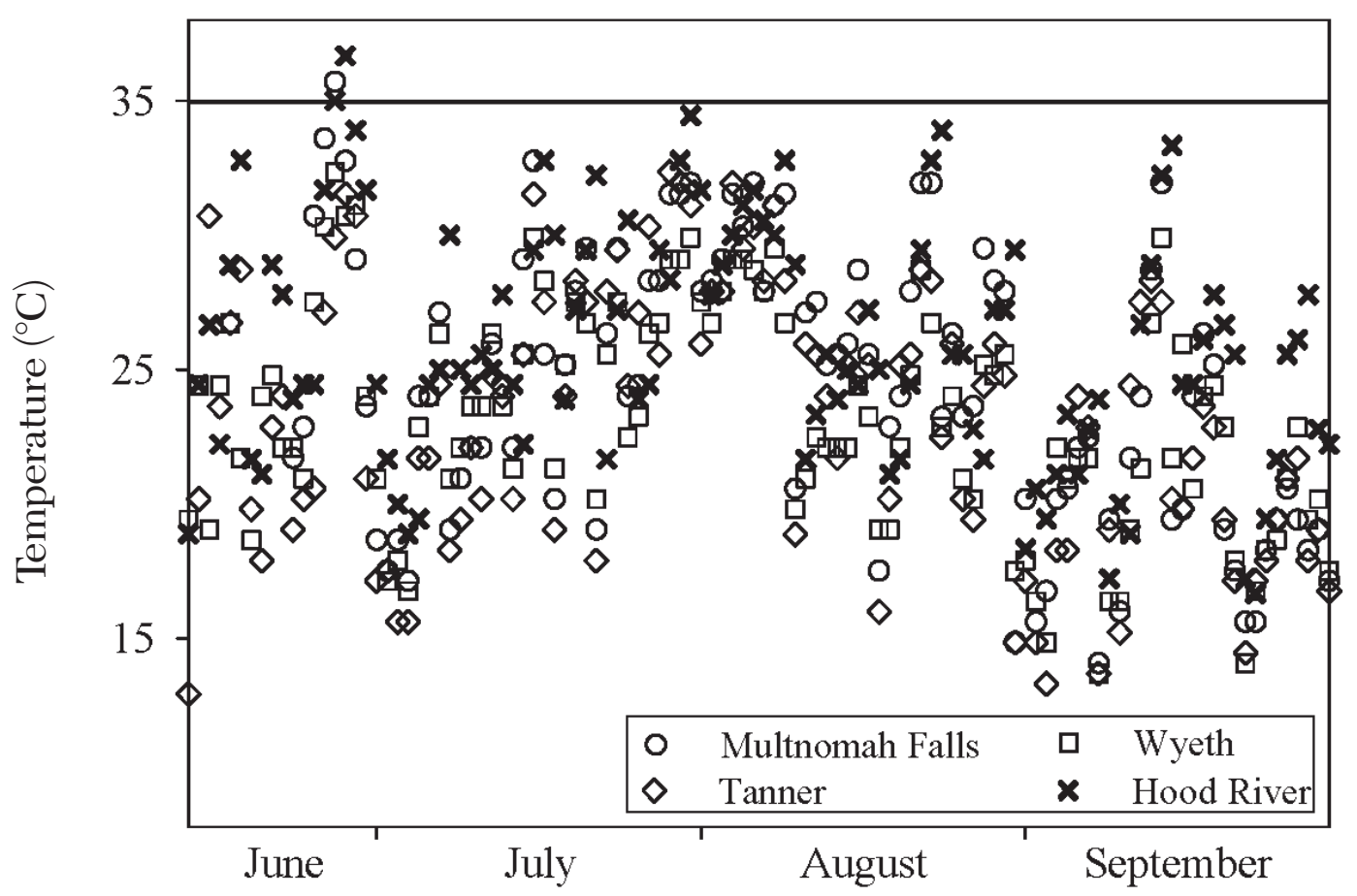

Fig. 1. Daily temperature maxima recorded at 3 pika-occupied sites and a weather station (Hood River) in the Columbia River Gorge, Oregon, during summer 2000.

days than the regional ATL for all pika habitat. No significant differences were found between the mean minimum and maximum daily temperatures recorded at Hood River from 1971 to 2000 and minima recorded at Hood River in winter $2000-2001(S=432.5, P=0.33)$ or maxima recorded in the summer of $2001(S=$ 101.0, $P=0.76$, Fig. 3). The 30 -year average daily minima also fell below the regional ATL for number of days $<0{ }^{\circ} \mathrm{C}(45 \%$ fewer days $)$ and exceeded the regional ATL for number of consecutive freeze-free days (2.4 times as many days, Table 1 ).

Snowfall was scant in Hood River and at Bonneville Dam during winter 2000-2001. At Hood River there was measurable snowfall on 25 days and snow on the ground for 33 days (median depth $0.8 \mathrm{~cm}$, range trace-16 $\mathrm{cm}$ ). The duration of snowcover for each event averaged 3 days. At Bonneville Dam there was only a $1-\mathrm{cm}$ snowfall on a single day. Pikaoccupied sites in the CRG averaged 43 freezethaw events, 4 days when temperatures were $<0{ }^{\circ} \mathrm{C}$ through the entire day, and 3 days when temperatures reached $<3{ }^{\circ} \mathrm{C}$ during winter 2000-2001.

\section{DisCUSSION}

American pika populations in the CRG are found at unusually low elevations compared with other populations at similar latitudes. Range-wide American pikas are now largely absent from most low-elevation habitats, due at least partially to physiological reasons. Ambient temperatures in the CRG were presumably warm enough to affect pikas physiologically, because for nearly $44 \%$ of the summer, daily temperature maxima exceeded 25.5 ${ }^{\circ} \mathrm{C}$ (Fig. 1), the ambient air temperature at which a caged pika died in the Sierra Nevada (Smith 1974). Smith (1974) and MacArthur and Wang (1974) showed that low-elevation American pikas otherwise tolerated such temperatures by using rockslides for shelter during behavioral thermoregulation. Comparable behaviors might be used by low-elevation pikas in the CRG, as summer vocalizations appeared crepuscular.

On a regional scale, most suitable pika habitats that offer rocky substrates with cool summer temperatures occur in montane areas. Pikas using montane habitat may require 


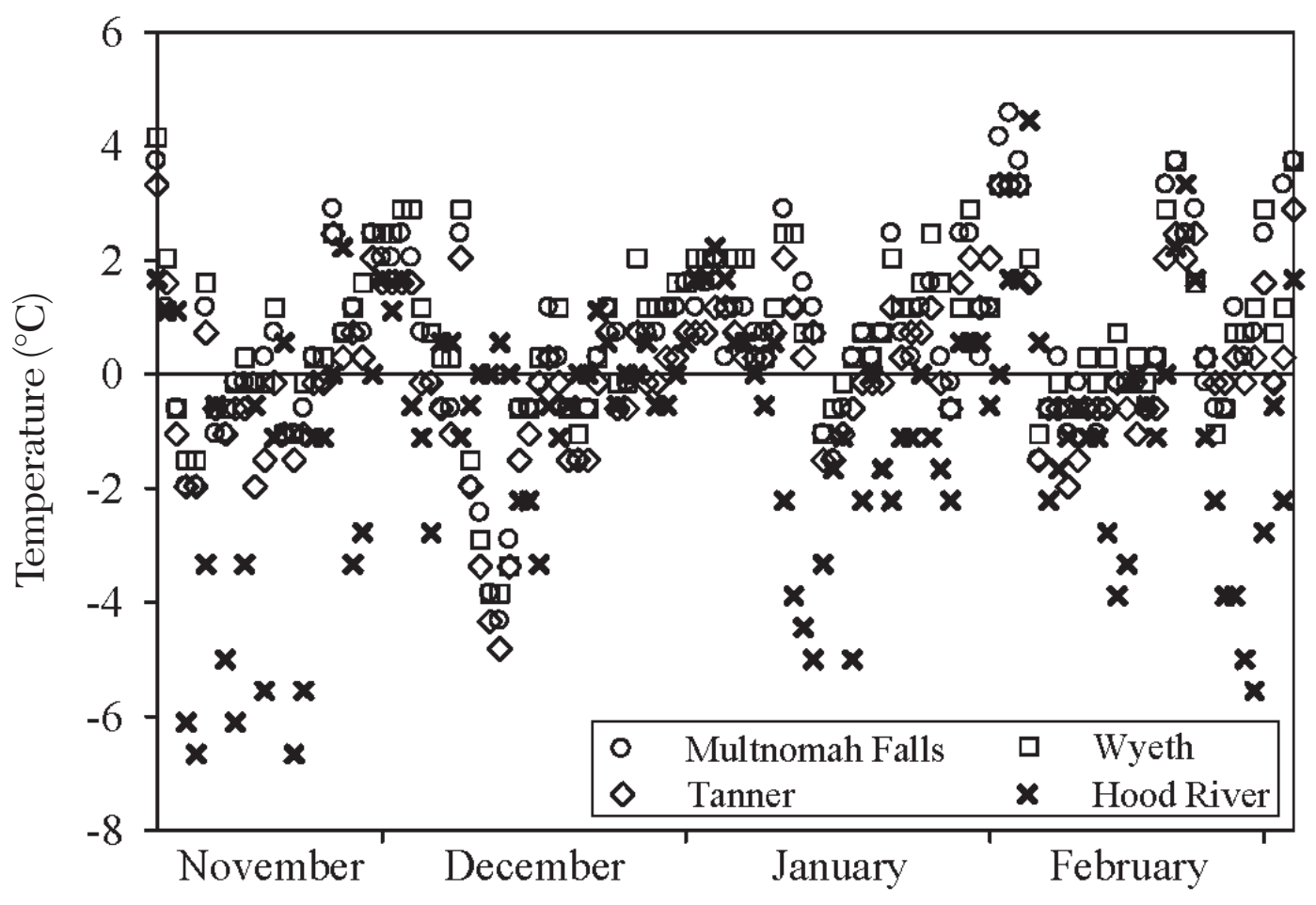

Fig. 2. Daily temperature minima recorded at 3 pika-occupied sites and a weather station (Hood River) in the Columbia River Gorge, Oregon, during autumn and winter 2000-2001.

long-winter conditions where temperatures and precipitation provide snowpack insulation to guard against extremely cold temperatures. Examination of local climate at low-elevation pika sites in the CRG shows that pikas that avoid physiological stress by their association with cool summer temperatures may not necessarily require prolonged cold winters. Assuming the CRG pikas are not part of a large series of sink populations (Kreuzer and Huntly 2003), pikas in the CRG have been known to successfully use this habitat for over 80 years-habitat that is exposed to frequent freeze-thaw cycles and notable amounts of freezing rain (Horsfall 1925, Roest 1953, Lynott 1966, Robbins and Cortinas 2002) despite little winter snowpack insulation. Snow-thaw events in the CRG did not appear to be followed by periods with acutely stressful freezing temperatures that could require a substantial increase in energy use for thermoregulation (Smith et al. 2004). Recent freezing-rain events recorded in other parts of the CRG (2004-2008, Western Regional Climate Center, www.wrcc.dri.edu) also suggest that these events may be short lived and followed by temperatures above $0{ }^{\circ} \mathrm{C}$, thereby reducing the potential for negative effects on pika thermoregulation and the potential for food inaccessibility (Morrison and Hik 2007, 2008).

By investigating summer and winter conditions at low-elevation pika habitat, scientists can gain a better understanding of the effects of climate on past and future distributions of American pikas. Hafner (1993) claimed that extant pikas are good biological indicators of short summers, long winters, high precipitation, and rocky habitat, based on the close relationship he found between the predicted minimum elevation of extant pikas and the elevation of fossil sites when he corrected for latitude, longitude, and changes in snowline. Because of this relationship, Hafner (1993) argued that the general climatic parameters for pikas remained relatively constant during the Late Quaternary, allowing reconstruction of the local environment surrounding fossil sites by use of the American pika as a biogeographic indicator species. Pika habitat in the CRG largely confirms Hafner's contention 


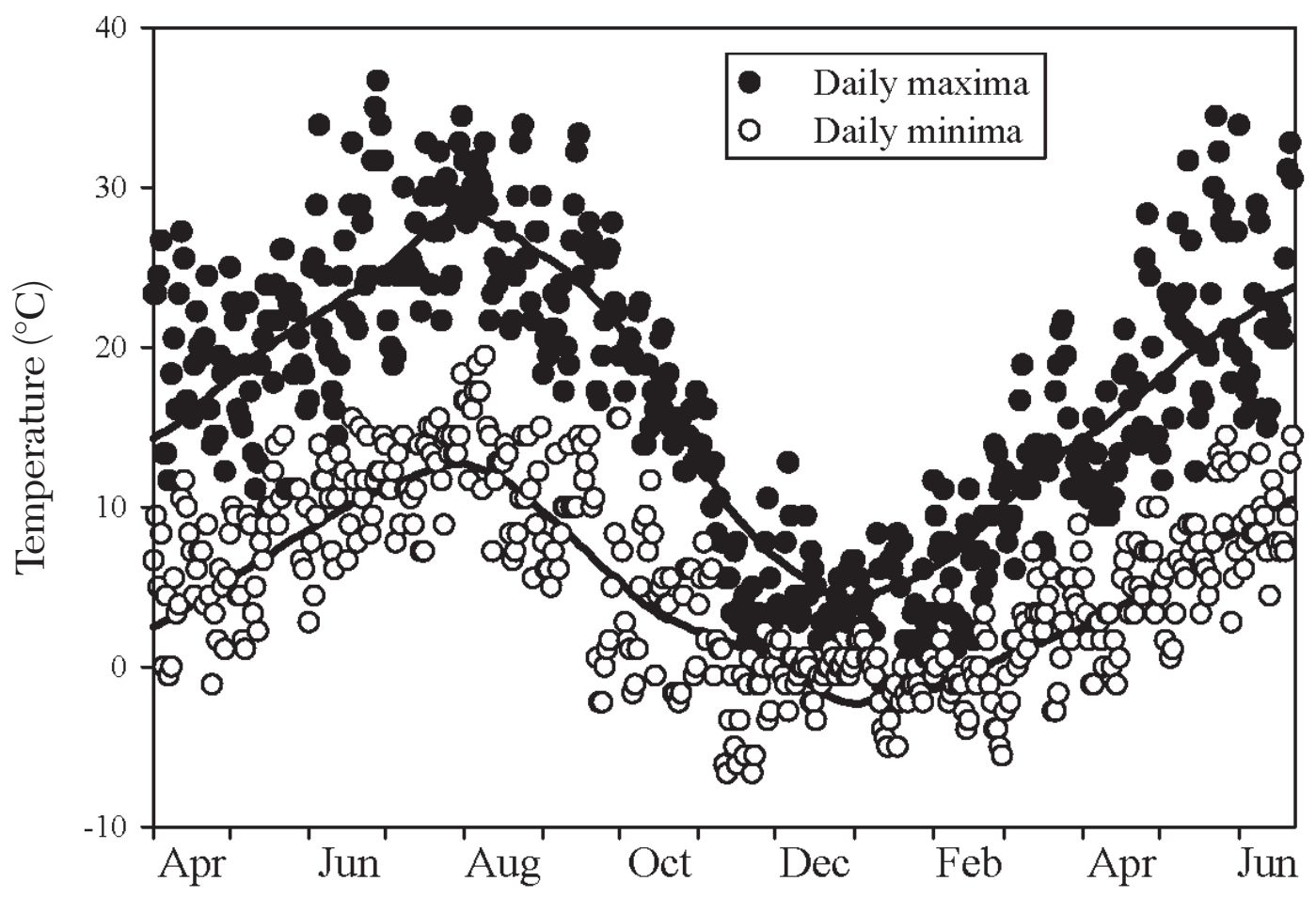

Fig. 3. Daily temperature maxima and minima recorded at Hood River, Oregon, between April 2000 and June 2001 compared with the average 30-year maxima and minima recorded from 1971 to 2000 . The top line represents the 30 year average daily maxima and the bottom line represents the 30 -year average daily minima.

(Lynott 1966). However, due to current temperatures in the CRG, pikas should not necessarily be used as biological indicators of longwinter conditions. Biologists anticipating the response of American pikas to climate change should consider that some low-elevation populations may not be negatively affected by the loss of winter snow cover. Long-winter climates may be obligatory only for pikas that experience many days with ambient temperatures significantly below $0{ }^{\circ} \mathrm{C}$, or at locales dependent on periglacial freeze-thaw processes for formation of talus habitat (e.g., southern Rocky Mountains; Hafner 1994). The mild winters pikas experience in the CRG may have been more widespread in certain areas during the late Wisconsinan (Spaulding et al. 1983). At that time both summer and winter conditions could have been mild enough to provide pikas a more extensive low-elevation distribution than might be hypothesized based on long-winter ATL derived from current regional conditions.

Using pikas as indicators of low summer temperatures (short summers) appears reasonable based on their current sensitivity to hyperthermia (MacArthur and Wang 1973, Smith 1974), their low vagility during warm conditions (Smith 1974), strong evidence that climatic warming restricted the distribution of pika populations historically (Grayson 2005), and evidence that warming may be linked to current extirpations (Beever et al. 2003, Smith et al. 2004). Pikas that inhabit regions without cool summer habitat have access to cool and possibly unique microhabitat locally (e.g., populations at Lava Beds National Monument and Craters of the Moon National Monument; Hafner 1993).

The thermal uniqueness of low-elevation habitats highlights the need for continued study of pika populations in the CRG, as advocated by Verts and Carraway (1998). In contrast to Oregon pikas in this study, the longitudinal range of pikas found below $300 \mathrm{~m}$ on the southfacing slopes (Washington side) of the CRG may be somewhat restricted. An analysis of differences between inhabited and uninhabited sites on both sides of the Columbia River 
could help determine how local climatic factors and habitat characteristics (e.g., subsurface rockslide temperatures, insolation and slope aspect, relative humidity, insulating capacity of rockslide vegetation, rock size, and rockslide isolation) contribute to rockslide occupancy while controlling for ambient temperature. To date, comparisons of local climate and physical habitat characteristics to seasonal microclimatic conditions (directly experienced by pikas) have been lacking. Since temperature measurements alone may not be a perfect proxy for thermal factors that influence pika persistence (Beever et al. 2008), comparisons between a variety of habitat characteristics may further address potential mechanisms for persistence of pikas in areas where climatic conditions might be physiologically stressful.

Local climatic comparisons between the habitats of CRG pikas and other low-elevation populations in the Pacific Northwest could provide further refinement of relevant climatic influences. The elevational range of American pikas in the Pacific Northwest has historically extended below $600 \mathrm{~m}$ in the Frazier River valley (Howell 1924), near the Pacific coast in southwestern British Columbia (Cowan 1954, David Nagorsen personal communication), and possibly elsewhere in the Cascade Mountains (Hall 1951, Roest 1953). Pika presence in low-elevation habitats should continue to be investigated (Beever et al. 2008) because of the recent extirpation of many newly recorded pika populations (Beever et al. 2003, E. Beever personal communication).

Pika foraging ecology may also be affected by climatic regimes atypical of the species' current geographic range. Because rockslides in the CRG were never covered by deep snowpack during winter and spring, pikas had direct access to fresh vegetation all year. During a total of 55 hours of surveys (this study) and 55 hours of behavioral observations (Simpson 2001, W. Simpson unpublished data) in the CRG, I observed only 3 instances of vegetation clippings presumably collected by pikas, no inactive haypiles, and no haying behavior. In each case, the clippings collected were considerably smaller than the size of a fist and consisted of species that were growing on the rockslide surface within inches of the clippings. This is conspicuous considering that other investigators have observed pikas preparing for winter by spending up to $55 \%$ of their surface activity time constructing haypiles (Sharp 1973, Conner 1983, Smith and Ivins 1984).

Haypiles are collected for use in seasons when vegetation is absent or inaccessible (Dearing 1997). Haying is costly in terms of energy and exposure to predators (Ivins and Smith 1983, Huntly 1987, Holmes 1991) and can be thermally stressful in warm, low-elevation habitats (Smith 1974). Therefore, it is uncertain what advantages haypiles would confer to pikas in areas where winter vegetation is plentiful and accessible, such as in the CRG. Dearing (1997) discussed the difficulties of quantifying haypile size. Pikas may store caches in inaccessibly deep parts of rockslides, making their detection by investigators difficult. However, most studies describe at least some notable haypile material either exposed on rockslide surfaces or observable by subsurface examination.

It is unknown whether pikas in the CRG occasionally collect small amounts of vegetation for immediate consumption, gather unusually small haypiles, or forgo haypile collection altogether. Currently there is no evidence that American pikas in the CRG use haypiles to withstand long periods of food inaccessibility.

Adjacent high-elevation populations of pikas on Mt. Hood, Oregon, gather relatively large haypiles (Frazier 1977, W. Simpson personal observation) and experience substantially more winter snow accumulation than low-elevation populations in the CRG. Such high variability in the number of detectible haypiles between adjacent populations may preclude large-scale comparisons of population size and growth when haypiles are used as an index of pika abundance (Morrison and Hik 2008). Describing haying behavior and measuring haypile characteristics across such an elevational and climatic gradient could expand the understanding of how abiotic conditions influence pika foraging ecology.

\section{ACKNOWLEDGMENTS}

I thank Jeb Bevers for field assistance and advice regarding this study. I benefited from discussions with David Nagorsen about British Columbian pikas. The comments of Andrew Smith and 2 anonymous reviewers helped improve the quality of the final manuscript. Special thanks go to Erik Beever for his valuable input on this manuscript. 


\section{Literature Cited}

Beever, E.A., P.F. Brussard, and J. Berger. 2003. Patterns of apparent extirpation among isolated populations of pikas (Ochotona princeps) in the Great Basin. Journal of Mammalogy 84:37-54.

Beever, E.A., J.L. Wilkening, D.E. McIvor, S.S. Weber, and P.S. Brussard. 2008. American pikas (Ochotona princeps) in northwestern Nevada: a newly discovered population at a low-elevation site. Western North American Naturalist 68:8-14.

Conner, D.A. 1983. Seasonal changes in activity patterns and the adaptive value of haying in pikas (Ochotona princeps). Canadian Journal of Zoology 61:411-416.

Cowan, I.M. 1954. The distribution of the pikas (Ochotona) in British Columbia and Alberta. Murrelet 35:20-24.

DEARING, M.D. 1997. The function of haypiles of pikas (Ochotona princeps). Journal of Mammalogy 78: 1156-1163.

FraziER, N.A.E. 1977. A behavioral study of a small group of pikas (Ochotona princeps) on Mt. Hood, Oregon. Master's thesis, Portland State University, Portland, OR.

GraYson, D.K. 2005. A brief history of Great Basin pikas. Journal of Biogeography 32:2103-2111.

GrinNELL, J. 1917. Field tests of theories concerning distributional control. American Naturalist 51:115-128.

HAFNER, D.J. 1993. North American pika (Ochotona princeps) as a Late Quaternary biogeographic indicator species. Quaternary Research 39:373-380.

1994. Pikas and permafrost: post-Wisconsin historical zoogeography of Ochotona in the southern Rocky Mountains, U.S.A. Arctic and Alpine Research 26:375-382.

Hall, E.R. 1951. A synopsis of North American Lagomorpha. University of Kansas Publications, Museum of Natural History 5:121-202.

Holmes, W.G. 1991. Predator risk affects foraging behaviour of pikas: observational and experimental evidence. Animal Behaviour 42:111-119.

Horsfall, R.B. 1925. The pika at sea level. Journal of Mammalogy 6:201-202.

HoweLL, A.H. 1924. Revision of the American pikas (genus Ochotona). North American Fauna 47:iv, 1-57.

Huntly, N.J. 1987. Influence of refuging consumers (pikas: Ochotona princeps) on subalpine meadow vegetation. Ecology 68:274-283.

Ivins, B.L., AND A.T. SMITH. 1983. Responses of pikas (Ochotona princeps: Lagomorpha) to naturally occurring terrestrial predators. Behavioral Ecology and Sociobiology 13:277-285.

Kreuzer, M.P., and N.J. Huntly. 2003. Habitat-specific demography: evidence for source-sink population structure in a mammal, the pika. Oecologia 134: 343-349.

LyNOTT, R.E. 1966. Weather and climate of the Columbia Gorge. Northwest Science 40:129-132.
MacArthur, R.A., and L.C.H. Wang. 1974. Behavioral thermoregulation in the pika Ochotona princeps: a field study using radiotelemetry. Canadian Journal of Zoology 52:353-358.

1973. Physiology of thermoregulation in the pika, Ochotona princeps. Canadian Journal of Zoology 51:11-16.

MorRison, S.F., AND D.S. Hik. 2007. Demographic analysis of a declining pika Ochotona collaris population: linking survival to broad-scale climate patterns via spring snowmelt patterns. Journal of Animal Ecology 76:899-907.

2008. When? Where? And for how long? Census design considerations for an alpine lagomorph, the collared pika (Ochotona collaris). Pages 103-113 in P.C. Alves, N. Ferrand, and K. Hackländer, editors, Lagomorph biology: evolution, ecology, and conservation. Springer Verlag, Berlin.

Robbins, C.C., AND J.V. CoRTinas. 2002. Local and synoptic environments associated with freezing rain in the contiguous United States. Weather and Forecasting $17: 47-65$.

Roest, A.I. 1953. Notes on pikas from the Oregon Cascades. Journal of Mammalogy 34:132-133.

SharP, P.L. 1973. Behavior of the pika (Ochotona princeps) in the Kananaskis region of Alberta. Master's thesis, University of Alberta, Edmonton, Canada.

SIMPSON, W. 2001. Foraging activities of the pika (Ochotona princeps): a comparison of two populations. Master's thesis, Portland State University, Portland, OR.

SмITH, A.T. 1974. The distribution and dispersal of pikas: influences of behavior and climate. Ecology 55: 1368-1376.

. 1978. Comparative demography of pikas (Ochotona): effect of spatial and temporal age-specific mortality. Ecology 59:133-139.

Smith, A.T., AND B.L. Ivins. 1984. Spatial relationships and social organization in adult pikas: a facultatively monogamous mammal. Zeitschrift für Tierpsychologie 66:289-308.

Smith, A.T., L. Weidong, and D.S. Hik. 2004. Pikas as harbingers of global warming. Species 41:4-5.

Spaulding, W.G., E.B. Leopold, and T.R. Van DevenDER. 1983. Late Wisconsin paleoecology of the American Southwest. Pages 259-293 in S.C. Porter, editor, Late-Quaternary environments of the United States. Volume 1, The Late Pleistocene. University of Minnesota Press, Minneapolis.

VerTs, B.J., AND L.N. CaRRaWAY. 1998. Land mammals of Oregon. University of California Press, Berkeley. $800 \mathrm{pp}$.

Received 9 May 2008 Accepted 16 January 2009 